\title{
Decreasing the expression of PICALM reduces endocytosis and the activity of $\beta$-secretase: implications for Alzheimer's disease
}

\author{
Rhian S. Thomas ${ }^{1}$, Alex Henson ${ }^{1}$, Amy Gerrish ${ }^{2,3}$, Lesley Jones ${ }^{2}$, Julie Williams ${ }^{2}$ and Emma J. Kidd ${ }^{*}$
}

\begin{abstract}
Background: Polymorphisms in the gene for phosphatidylinositol binding clathrin assembly protein (PICALM), an endocytic-related protein, are associated with a small, increased risk of developing Alzheimer's disease (AD), strongly suggesting that changes in endocytosis are involved in the aetiology of the disease. We have investigated the involvement of PICALM in the processing of amyloid precursor protein (APP) to understand how PICALM could be linked to the development of AD. We used siRNA to deplete levels of PICALM, its isoforms and clathrin heavy chain in the human brain-derived $\mathrm{H} 4$ neuroglioma cell line that expresses endogenous levels of APP. We then used Western blotting, ELISA and immunohistochemistry to detect intra- and extracellular protein levels of endocytic-related proteins, APP and APP metabolites including $\beta$-amyloid (A $\beta$ ). Levels of functional endocytosis were quantified using ALEXA 488-conjugated transferrin and flow cytometry as a marker of clathrin-mediated endocytosis (CME).

Results: Following depletion of all the isoforms of PICALM by siRNA in $\mathrm{H} 4$ cells, levels of intracellular APP, intracellular $\beta$-C-terminal fragment ( $\beta$-CTF) and secreted SAPP $\beta$ (APP fragments produced by $\beta$-secretase cleavage) were significantly reduced but A 40 was not affected. Functional endocytosis was significantly reduced after both PICALM and clathrin depletion, highlighting the importance of PICALM in this process. However, depletion of clathrin did not affect APP but did reduce $\beta$-CTF levels. PICALM depletion altered the intracellular distribution of clathrin while clathrin reduction affected the subcellular pattern of PICALM labelling. Both PICALM and clathrin depletion reduced the expression of BACE1 mRNA and PICALM siRNA reduced protein levels. Individual depletion of PICALM isoforms 1 and 2 did not affect APP levels while clathrin depletion had a differential effect on the isoforms, increasing isoform 1 while decreasing isoform 2 expression.
\end{abstract}

Conclusions: The depletion of PICALM in brain-derived cells has significant effects on the processing of APP, probably by reducing CME. In particular, it affects the production of $\beta$-CTF which is increasingly considered to be an important mediator in AD independent of A $\beta$. Thus a decrease in PICALM expression in the brain could be beneficial to slow or prevent the development of AD.

Keywords: Alzheimer's disease, Amyloid precursor protein, $\beta$-C-terminal fragment, $\beta$-Secretase, Clathrin-mediated endocytosis, PICALM

\footnotetext{
*Correspondence: KiddEJ@cf.ac.uk

1 School of Pharmacy and Pharmaceutical Sciences, Cardiff University,

Redwood Building, King Edward VII Avenue, Cardiff CF10 3NB, UK

Full list of author information is available at the end of the article
} 


\section{Background}

In 2009 Genome Wide Association Studies (GWAS) were published describing polymorphisms in a number of genes associated with an increased risk of developing Alzheimer's disease (AD) including PICALM (phosphatidylinositol binding clathrin assembly protein) [1,2]. PICALM is involved in clathrin-mediated endocytosis [3]. Subsequently, the large IGAP (International Genomics of Alzheimer's disease Project) study identified further genes encoding the endocytic proteins BIN1 (bridging integrator 1) and SORL1 (sortilin-related receptor) that reached genome-wide significance $[2,4,5]$. Pathway analysis of the IGAP study [4] identified a number of biological pathways associated with AD including the regulation of endocytosis, thus emphasising the importance of this pathway in the pathogenesis of AD and suggesting areas for development of new therapies [3].

The amyloid cascade hypothesis is the leading theory to explain the aetiology of $\mathrm{AD}[6]$, suggesting that understanding how the production of $\beta$-amyloid $(A \beta)$ from amyloid precursor protein (APP) is controlled should improve intervention strategies. After synthesis, some APP is transported via the secretory pathway to the cell surface and internalised by endocytosis for processing including cleavage by one of two routes $[7,8]$. In the amyloidogenic pathway, $\beta$-secretase (identified as $\beta$-site APP cleaving enzyme or BACE1) cleaves APP to give two fragments, sAPP $\beta$ and C99 [9-12]. The $\gamma$-secretase complex then cleaves $\mathrm{C} 99$ to produce $\mathrm{A} \beta$ and a $\mathrm{C}$-terminal fragment (CTF) [12-15]. The alternative non-amyloidogenic pathway involves cleavage of APP by $\alpha$-secretase within the $A \beta$ region to release SAPP $\alpha$ and precludes the formation of $A \beta[16,17]$. It is thought that most amyloidogenic processing of APP occurs after endocytosis in the endocytic/lysosomal system [18]. Endocytosis is thus central to the production of $A \beta$ as it controls where APP is localised in the cell and which enzymes it encounters [19].

Altered CME has been described previously in AD. Early endocytic changes (an increase in number and size of Rab5-positive endosomes) have been seen in postmortem AD brains [20,21]. Inhibition of CME in vivo in APP transgenic mice and dynamin-dependent endocytosis in vitro lowered $A \beta$ levels $[22,23]$, while upregulation of endocytosis increased APP metabolism and A $\beta$ secretion [18]. Therefore endocytosis is strongly implicated in AD pathogenic processes.

PICALM is involved in the recruitment of clathrin and other proteins to the membrane and thus regulates the formation of clathrin-coated pits and vesicles in CME [24]; though how it might be involved in endocytosis in $\mathrm{AD}$ remains unclear. However, subjects carrying the $\mathrm{AD}$ risk alleles in PICALM and Clusterin show significantly poorer episodic memory, a marker for AD onset [25].
In yeast, deletion of PICALM homologues protected against $A \beta$-induced toxicity [26]. In contrast, the presence of PICALM protective alleles appeared to be associated with an increase in PICALM mRNA expression in human brain [27] and to protect against senile plaque development [28]. Decreased PICALM expression has been noted in $\mathrm{AD}$ brains along with abnormal cleavage fragments of PICALM and the association of PICALM with neurofibrillary tangles [29]. Thus PICALM may play an important role in $\mathrm{AD}$, but the mechanism by which it does this is unclear. Since the processing of APP to A $\beta$ is dependent on CME, our study aimed to investigate the contribution of PICALM to modulating the metabolism of APP and whether endocytotic processes were involved in that modulation.

We used the human brain-derived $\mathrm{H} 4$ neuroglioma cell line that expresses endogenous levels of APP as we wanted to look at the effects of PICALM on physiologically relevant levels of APP, more relevant to the situation found in $A D$ patients. We found that these cells expressed PICALM isoforms 1 and 2. Having depleted levels of PICALM by siRNA targeting all four isoforms, we showed that the levels of intracellular APP, the intracellular $\beta$-C-terminal fragment $(\beta-C T F)$ and secreted sAPP $\beta$ (APP fragments produced by $\beta$-secretase cleavage) were significantly reduced but $A \beta 40$ itself was not affected. Functional CME measured by transferrin uptake was significantly reduced after both depletion of PICALM and clathrin heavy chain ( $\mathrm{CHC}$ ). In contrast, depletion of clathrin did not affect APP levels but did reduce those of $\beta$-CTF. PICALM depletion altered the intracellular distribution of clathrin with less staining found in the perinuclear transgolgi region while clathrin depletion affected the subcellular pattern of PICALM labelling. Both PICALM and clathrin depletion reduced the expression of BACE1 mRNA and PICALM siRNA reduced protein levels. In contrast to the findings for depletion of all PICALM isoforms, individual depletion of PICALM isoforms 1 and 2 by specific siRNAs did not affect APP levels. Clathrin depletion had a more complicated differential effect on the isoforms, increasing isoform 1 protein and mRNA expression while decreasing isoform 2 protein expression but not affecting mRNA levels.

\section{Results \\ Effects of siRNA to total PICALM on PICALM mRNA and protein expression}

In $\mathrm{H} 4$ cells, we detected two bands for PICALM using Western blotting with molecular masses of $72.2 \pm 0.4$ and $65.8 \pm 0.9 \mathrm{kDa}$ (Fig. 1a). Four main isoforms (isoforms 1-4) of PICALM have been identified [30] [NCBI RefSeq:NP_009097.2, NP_001008660.1, 

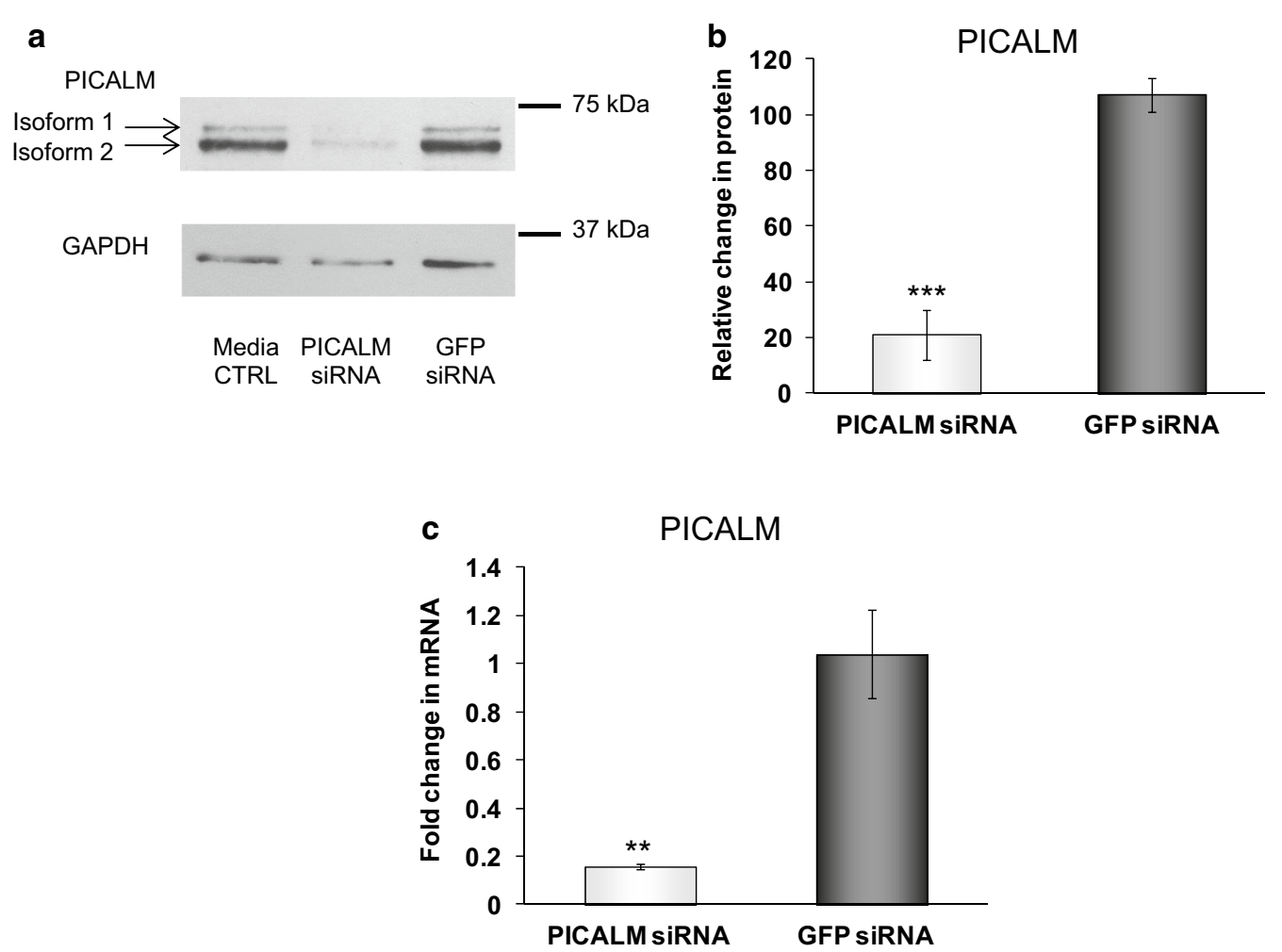

Fig. 1 PICALM levels in $\mathrm{H} 4$ cells following siRNA treatments. a Representative immunoblot of PICALM after transfecting $\mathrm{H} 4 \mathrm{cells}$ for $48 \mathrm{~h}$ with control siRNA (GFP siRNA) or siRNA targeting PICALM (PICALM siRNA) and $\mathbf{b}$ following densitometric analysis. Data are presented as mean \pm SEM as a percentage of the untreated media control after normalisation to house-keeping protein levels, $n=8,{ }^{* * *} \mathrm{p}<0.001$ significantly different to GFP siRNA with an unpaired Student's $t$ test. c PICALM mRNA expression levels using quantitative PCR, normalised to the housekeeping gene $18 S$ and relative to the untreated cells. Data are presented as mean $\pm S E M, n=6,{ }^{* *} p<0.01$ significantly different to GFP siRNA with Mann-Whitney-U

NP_001193875.1, and NP_001193876.1, respectively]. It is likely that the $72.2 \mathrm{kDa}$ band equates to isoform 1 [NCBI RefSeq:NP_009097.2] with a predicted mass of $70.6 \mathrm{kDa}$ and the $65.8 \mathrm{kDa}$ band to isoform 2 [NCBI RefSeq:NP_001008660.1] with a predicted mass of $66.3 \mathrm{kDa}$. We saw no evidence of bands with a predicted mass of $69.9 \mathrm{kDa}$ or $59.9 \mathrm{kDa}$, equating to isoforms 3 [NCBI RefSeq:NP_001193875.1] and 4 [NCBI RefSeq:NP_001193876.1], respectively, in our cells.

Using an siRNA sequence directed against all the isoforms of PICALM (Seq. A), we significantly reduced the total levels of PICALM to $17.9 \pm 6.2 \%$ of levels in control cells incubated with siRNA to GFP where PICALM levels were unaffected (Fig. 1b). In parallel, PICALM mRNA levels were reduced to $16.3 \pm 1.8 \%$ of those in GFP control siRNA cells (Fig. 1c). In immunocytochemistry, total PICALM depletion greatly reduced the marked punctate cytoplasmic and membrane-associated staining for PICALM seen in GFP control cells (Fig. 2a, b). There was no apparent perinuclear labelling seen for PICALM in GFP control cells (Fig. 2a).
siRNA to PICALM did not have any significant effect on cell viability measured using the MTS assay with absorbance levels of $98 \pm 4.6$ and $91.4 \pm 2.3 \%$ of the media control after treatment with siRNA to GFP and PICALM, respectively. There was also no significant difference in mean cell numbers as a percentage of the media control after treatment with siRNA targeting PICALM $(56.2 \pm 15.4 \%)$ compared to mean cell numbers following treatment with siRNA targeting GFP $(82.0 \pm 8.2)$.

\section{Effects of siRNA to total PICALM on endocytosis}

Having demonstrated an extensive reduction in the levels of PICALM, we investigated whether other proteins involved in CME were affected by siRNA to PICALM. Figure 3 shows that neither levels of $\mathrm{CHC}$ nor dynamin II were significantly affected by the reduction in PICALM levels. In addition, siRNA to PICALM had no significant effect on $\mathrm{CHC}$ mRNA with a reduction in mRNA levels for $\mathrm{CHC}$ to $98.2 \pm 17.5 \%$ of those in GFP control siRNA cells (data not shown). However, 


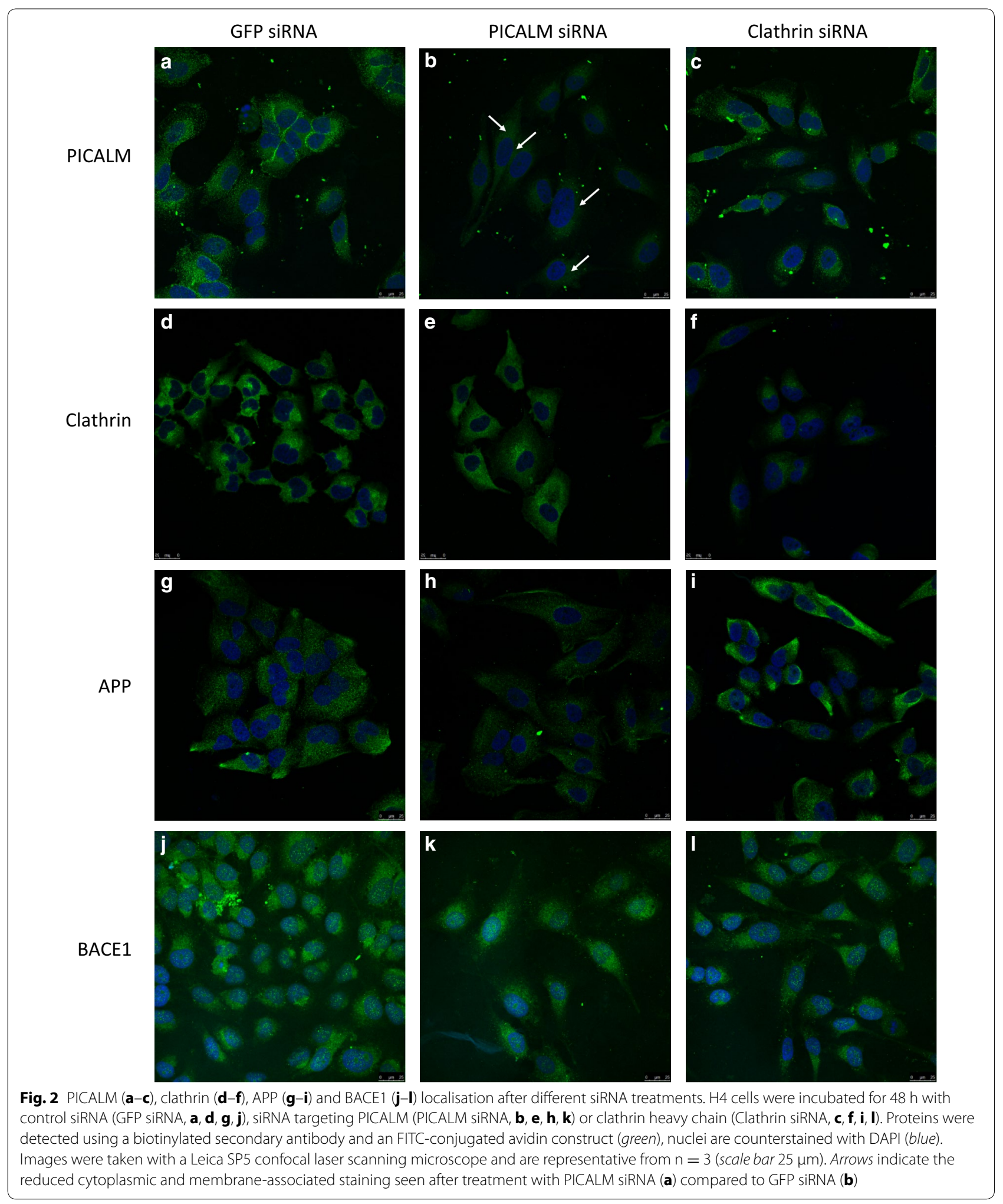

although clathrin levels overall were unaltered, we did see a reduction in the labelling for clathrin in the perinuclear region of cells depleted of PICALM compared to control cells, probably representing the transgolgi network (Fig. 2d, e). Furthermore, depletion of total PICALM significantly reduced the uptake of transferrin 


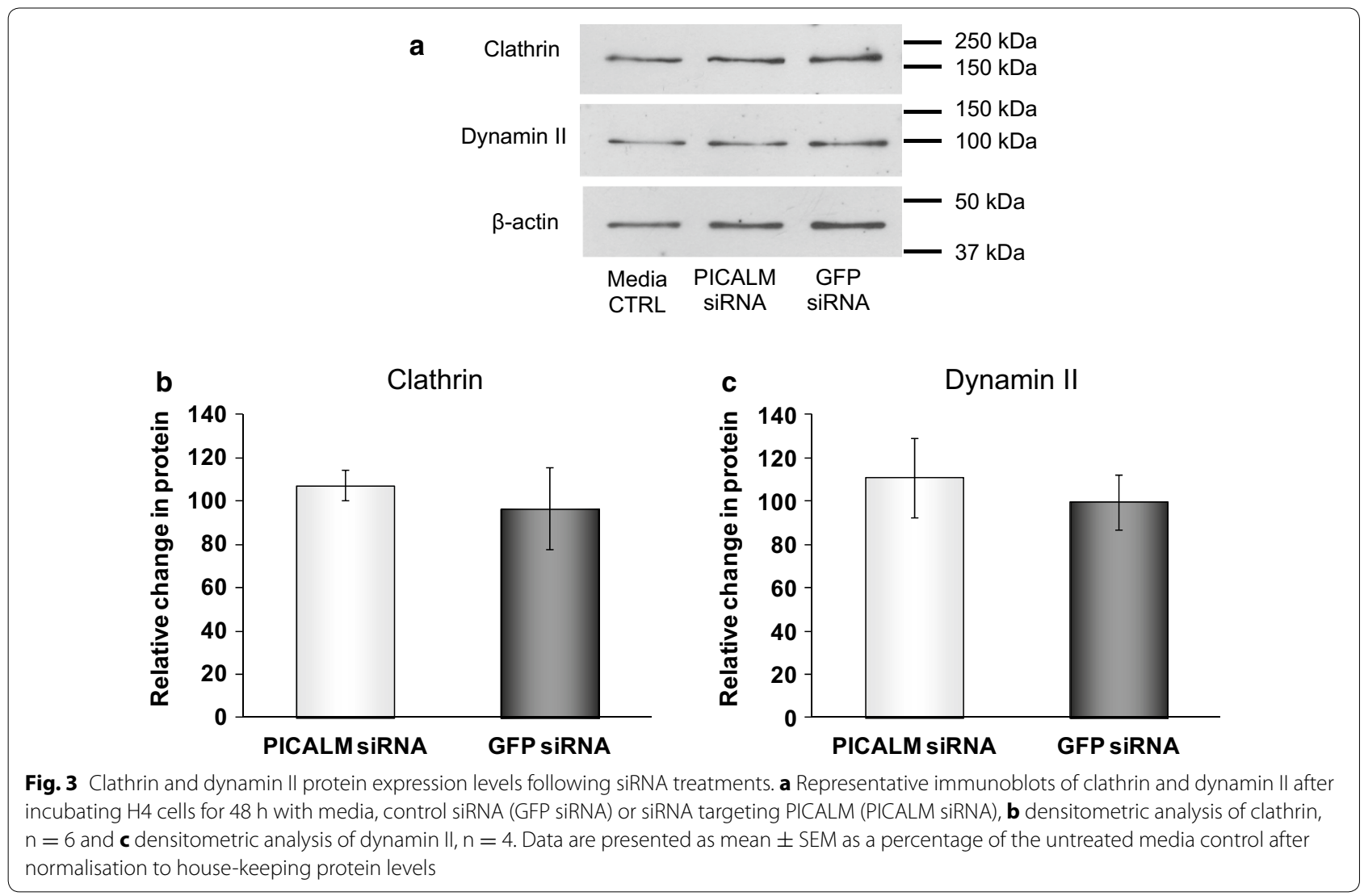

to $75.9 \pm 2.7$ and $71.2 \pm 1.7 \%$ of GFP levels after 15 and 30 min, respectively (Fig. 4).

\section{Effects of siRNA to total PICALM on the metabolism of APP} siRNA to total PICALM significantly reduced the expression of APP to $73.3 \pm 3.4 \%$ of the GFP control levels in $\mathrm{H} 4$ cells (Fig. 5a). We repeated the experiment looking at APP levels using a different, but equally effective, siRNA to PICALM (Seq. B) which reduced PICALM levels to $8.2 \pm 4.4 \%$ of GFP control levels. This siRNA had a similar effect on APP expression, reducing it to $85.9 \pm 4.2 \%$ of GFP levels (Fig. 5b). Reduced levels of APP protein after PICALM siRNA were also seen by immunocytochemistry in $\mathrm{H} 4$ cells but the distribution of intracellular APP did not appear to be affected (Fig. 2g, h). However, the levels of $A \beta 40$ were not affected by PICALM depletion (Fig. 5c). A 442 could not be measured in the H4 cells as the levels were below the detection limits of ELISAs (data not shown). Further investigation of the fragments of APP found that SAPP $\alpha$ was unaffected by reducing PICALM expression (data not shown). In contrast, the proportion of sAPP $\beta$ to sAPP $\alpha$ (expressed as a percentage) was significantly reduced by total PICALM siRNA to $59.5 \pm 7.2 \%$ of GFP control levels (Fig. $5 \mathrm{~d}$ ). $\beta$ CTF levels were significantly reduced to $52.7 \pm 7.8 \%$ of GFP levels

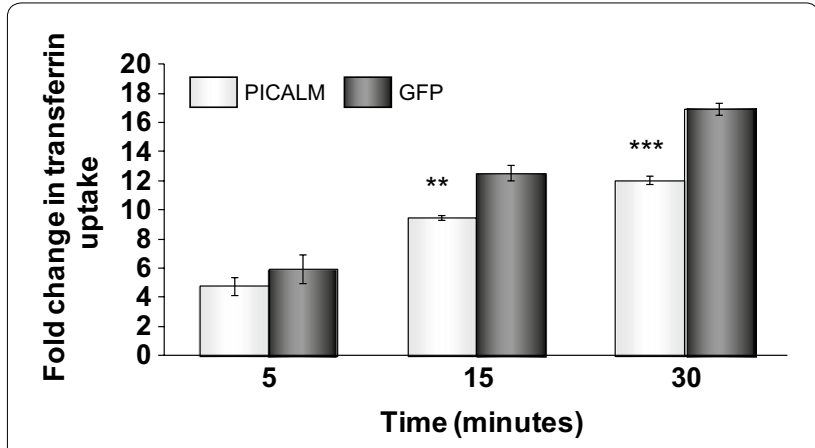

Fig. 4 Effect of PICALM siRNA on clathrin-mediated endocytosis. H4 cells were incubated with either control siRNA (GFP siRNA) or siRNA targeting PICALM (PICALM siRNA) prior to incubation with $100 \mathrm{nM}$ Alexa488-Tf for 5, 15 or 30 minutes then trypsinised and analysed by flow cytometry. Mean fluorescent intensity data for the uptake of Alexa488-Tf are expressed as fold change over untreated control cells (0 min Alexa488-Tf) and are mean $\pm \mathrm{SEM}{ }^{* * *} \mathrm{p}<0.001,{ }^{* *} \mathrm{p}<0.01$ significantly different to GFP siRNA with an unpaired Student's $t$ test, $n=3$

(Fig. 5e). In contrast to the effect on protein expression, mRNA levels for APP were unaffected by treatment with siRNA to PICALM compared to GFP (Fig. 5f). However, PICALM siRNA significantly reduced the amount of 

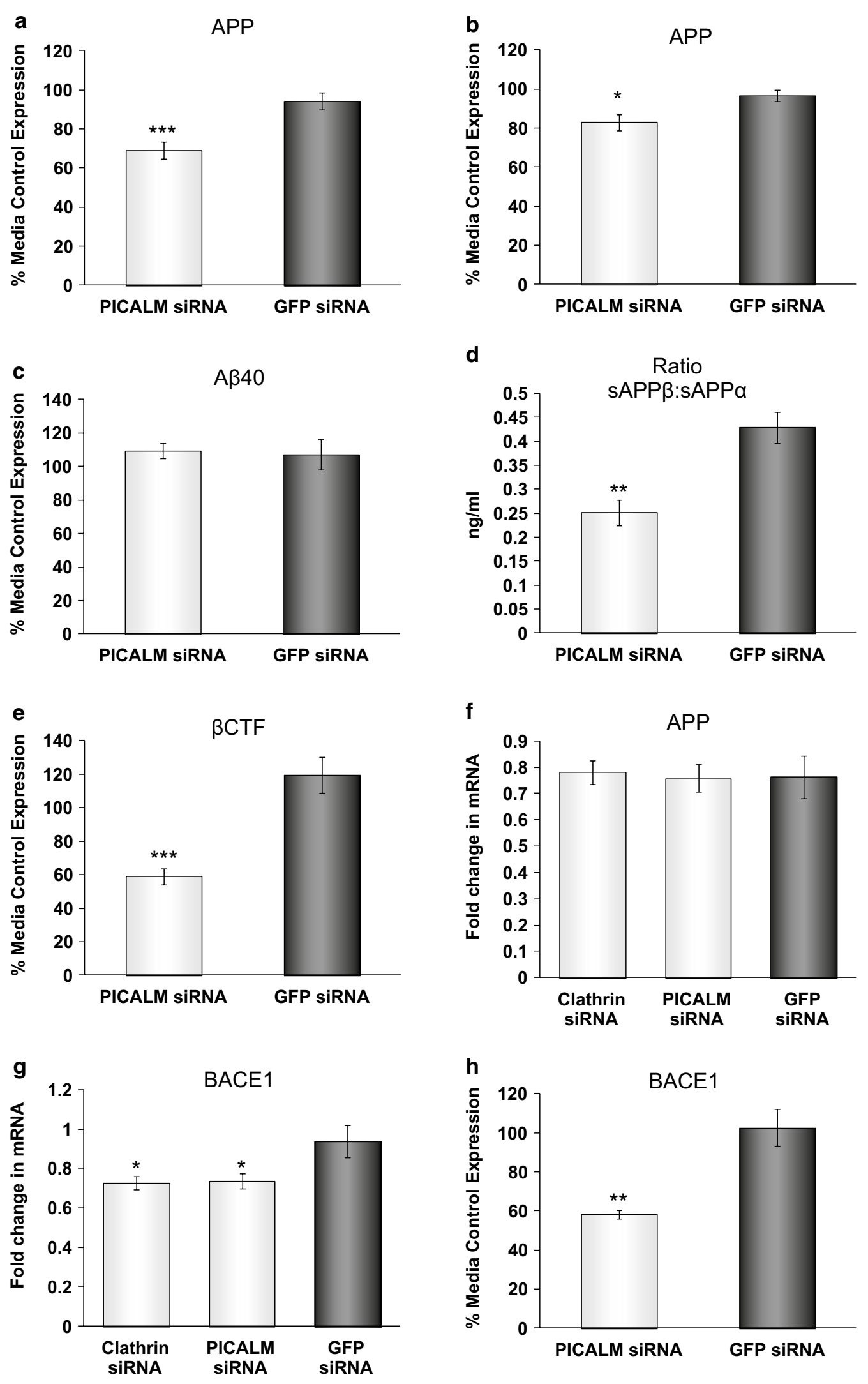
(See figure on previous page.)

Fig. 5 Effects of PICALM and clathrin siRNA on APP processing. H4 cells were incubated with media, control siRNA (GFP siRNA), siRNA targeting PICALM (PICALM siRNA sequence A or B) or clathrin heavy chain (Clathrin siRNA) for $48 \mathrm{~h}$. Levels of APP after treatment with (a, PICALM siRNA Seq A) and (b, PICALM siRNA Seq B), c AB40, d SAPPB:SAPPa, e $\beta C T F$ and $\mathbf{h}$ BACE1 as detected by ELISA. Data are expressed as \% of media control $(\mathbf{a}-\mathbf{c}, \mathbf{e}, \mathbf{h})$ and are mean $\pm \mathrm{SEM},{ }^{*} \mathrm{p}<0.05,{ }^{*} \mathrm{p}<0.01,{ }^{* * *} \mathrm{p}<0.001$ significantly different to GFP siRNA with an unpaired Student's $t$ test, $\mathrm{n}=11$ (a) $\mathrm{n}=4(\mathbf{b}), \mathrm{n}=5(\mathbf{c}) \mathrm{n}=4(\mathbf{d}), \mathrm{n}=7(\mathbf{e}), \mathrm{n}=4(\mathbf{h})$. f APP and $\mathbf{g}$ BACE1 mRNA expression levels measured using quantitative PCR, normalised to the housekeeping gene POLR2A and relative to the untreated cells. Data are expressed as mean $\pm S E M,{ }^{*} p<0.05$ significantly different to GFP siRNA with one-way analysis of variance and Dunnett's multiple comparison test $n=6$. Unless specified, cells were treated with siRNA targeting PICALM sequence $\mathrm{A}$

BACE1 mRNA compared to GFP siRNA to $80.5 \pm 6.3 \%$ (Fig. 5g). There was also a significant decrease in BACE1 protein levels to $57.6 \pm 2.9 \%$ of GFP levels as measured by ELISA following treatment with PICALM siRNA (Fig. 5h). However, no apparent differences were detectable in the amount or distribution of staining for BACE1 after PICALM depletion ( $\beta$-secretase, Fig. 2 j, k).

\section{Association of PICALM GWAS SNPs with PICALM isoform expression}

Using the Gibbs et al. [31] eQTL dataset (150 healthy brains) and the UK Brain Expression Consortium eQTL dataset [32] (134 healthy brains) we found that the risk (major, G) allele of the most significant SNP in PICALM rs3851179 [2], and the risk allele (major, G) of the most significant SNP in PICALM from IGAP rs10792832 [4], are both associated with a significant decrease in PICALM isoform 2 mRNA expression in the frontal ( $r$ 10792832 $\mathrm{p}=0.029 ; \mathrm{rs} 38581179 \mathrm{p}=0.022)$ and temporal cortex $(\mathrm{rs} 10792832 \mathrm{p}=0.019 ; \mathrm{rs} 38581179$ $\mathrm{p}=0.014)$ and the medulla from the Trabzuni dataset [32] (rs3851179 and rs10792832 p = 0.011). However, there was no significant change in the expression of PICALM isoform 1 mRNA associated with either rs3851179 or rs10792832.

\section{Effects of siRNA to PICALM isoforms on PICALM mRNA and protein expression}

Given that the PICALM SNPs were associated with differential changes in the expression of the isoforms of PICALM, we examined the contribution of the isoforms of PICALM to its functions in endocytosis and potential involvement with the processing of APP. We designed siRNA to the two most abundant isoforms we identified in the H4 cells, isoforms 1 and 2. Figure 6a, b shows that an siRNA to isoform 1 significantly depleted the expression of this isoform to $19.3 \pm 8.6 \%$ of GFP levels, without significantly affecting isoform 2 . It was very difficult to design an siRNA for isoform 2 which did not have a significant effect on isoform 1 because of their overlapping sequences and the most selective siRNA for isoform 2 produced a smaller significant reduction to $48.2 \pm 9.0$ of GFP levels, without affecting isoform 1 (Fig. 6a, c). mRNA for isoforms 1 and 2 were both significantly reduced to $20.7 \pm 2.3$ and $23.8 \pm 1.9$, respectively, from GFP levels by siRNA to total PICALM (Fig. 6d, e).

\section{Effects of siRNA to isoforms 1 and 2 of PICALM on the metabolism of APP}

In contrast to the siRNA to total PICALM which significantly reduced APP levels, neither siRNA to isoform 1 nor isoform 2 significantly affected the levels of APP (Fig. 7a). Similarly, only the siRNA to total PICALM significantly reduced the cleavage of APP to the $\beta C T F$ fragment with the siRNA to isoforms 1 and 2 having no significant effect (Fig. 7b).

\section{Effects of siRNA to clathrin heavy chain on endocytosis and APP expression}

Having shown that depletion of PICALM affected functional endocytosis, clathrin localisation and APP processing, we examined whether knocking down clathrin itself would have any effect on PICALM or APP processing. Using siRNA to CHC and compared to GFP siRNA-treated control cells, we significantly reduced the expression of $\mathrm{CHC}$ protein to $14.9 \pm 1.5 \%$ (Fig. 8a, b), CHC mRNA to $17.3 \pm 3.9 \%$ (Fig. 8c) and greatly reduced cell staining for clathrin (Fig. 2f). This reduction in clathrin produced concomitant significant decreases in CME to $81.9 \pm 7.4,75.9 \pm 2.7$ and $71.2 \pm 6.4 \%$ of GFP levels after 5, 15 and $30 \mathrm{~min}$, respectively (Fig. 8d). siRNA to CHC had no effect at all on the mRNA for total PICALM (data not shown). It did not significantly affect the total amount of PICALM at the protein level but did differentially affect the expression of isoforms 1 and 2 of PICALM, resulting in a significant decrease in isoform 2 expression to $38.5 \pm 9.2 \%$ of GFP control levels (Fig. 9a, c). There was also a concomitant increase in isoform 1 but this did not reach significance (Fig. 9a, b). At the mRNA level siRNA to CHC significantly increased isoform 1 mRNA to $426.4 \pm 61.5 \%$ (Fig. 6c) but had no significant effect on isoform 2 mRNA (Fig. 6d). Following siRNA to CHC, labelling for PICALM was altered with more pronounced staining seen in the cytoplasm and less 
a

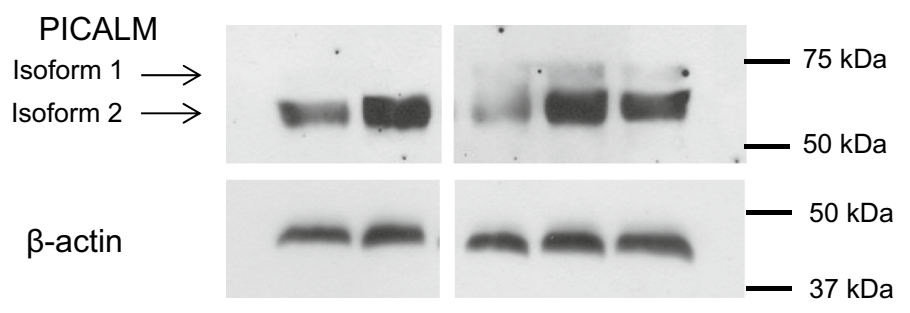

b
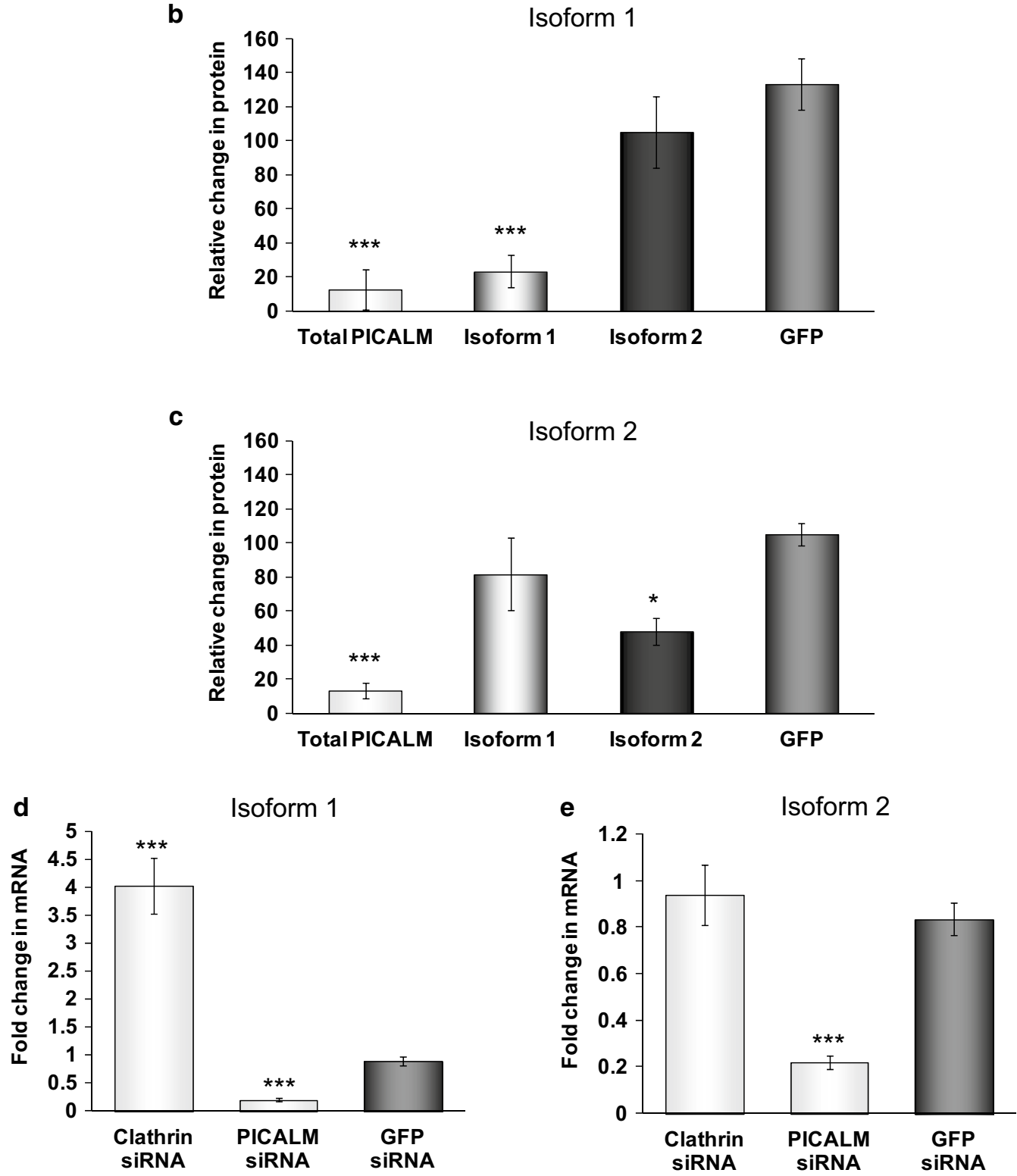
(See figure on previous page.)

Fig. 6 PICALM levels following siRNA treatments targeting isoforms 1 and 2 of PICALM, total PICALM and clathrin. a Representative immunoblots of PICALM isoforms after incubating H4 cells for $48 \mathrm{~h}$ with media or siRNA targeting either total PICALM (sequence A), PICALM isoform 1, PICALM isoform 2, clathrin or GFP for $48 \mathrm{~h}$. b Densitometric Western blot analysis of the levels of PICALM, isoform 1 and $\mathbf{c}$ isoform 2. Data are presented as a percentage of the untreated media control after normalisation to house-keeping protein levels and are mean $\pm S E M, n=6-7,{ }^{*} p<0.05$,

${ }^{* * *} p<0.001$ significantly different to GFP siRNA following one-way analysis of variance and Dunnett's multiple comparison test (b) or Kruskal-Wallis test and Dunn's multiple comparison test (c). d PICALM isoform 1 and e PICALM isoform 2 mRNA expression levels measured using quantitative $P C R$, normalised to the housekeeping gene POLR2A and relative to the untreated cells, $n=5-6,{ }^{* * *} p<0.001$ significantly different to GFP siRNA following one-way analysis of variance and Dunnett's multiple comparison test

at the membrane (Fig. 2c). However, unlike the effect of the decrease in PICALM on APP processing, this reduction in $\mathrm{CHC}$ expression did not significantly alter the levels of APP (Fig. 9d) but did significantly reduce the levels of $\beta C$ TF to $67.4 \pm 4.5 \%$ of GFP levels (Fig. 9e). Similarly to PICALM siRNA, mRNA levels for APP were unaffected by CHC siRNA (Fig. 5f) but BACE1 mRNA was significantly reduced by $\mathrm{CHC}$ siRNA to $79.6 \pm 6.0 \%$ (Fig. 5g). BACE1 protein levels measured by ELISA were not significantly altered by CHC siRNA (Fig. 9f). The labelling for APP and BACE1 were not affected by siRNA to $\mathrm{CHC}$ (Fig. 2i, l).

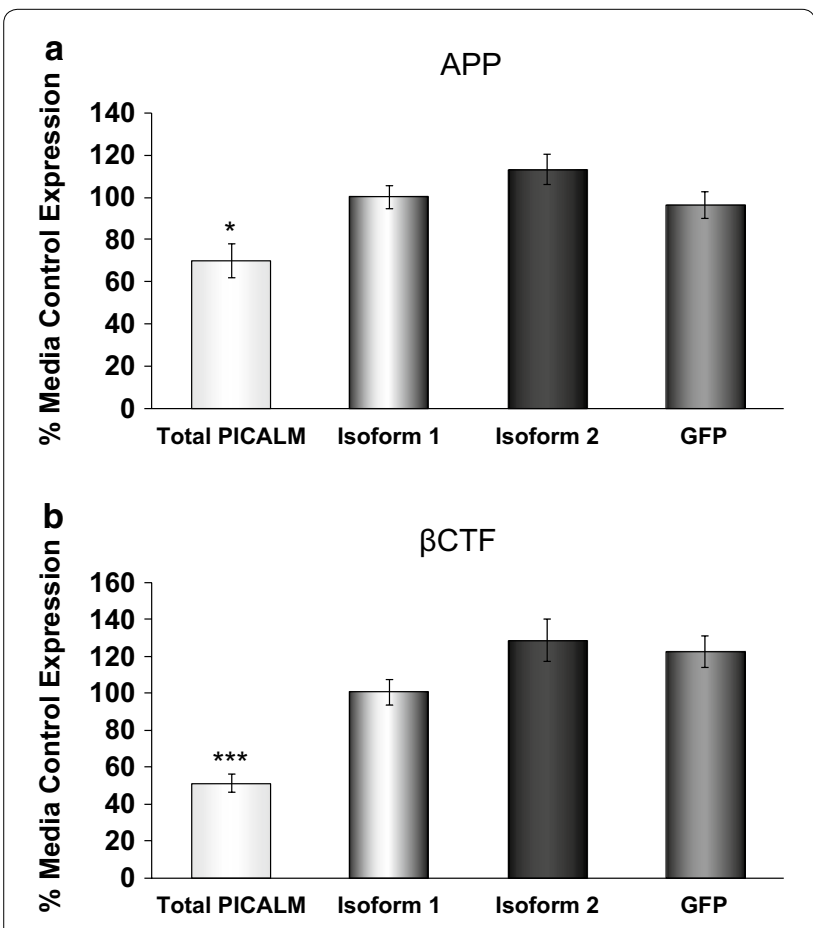

Fig. 7 Effects of PICALM siRNA targeting isoforms 1 and 2 of PICALM on APP processing. Levels of $\mathbf{a}$ APP and $\mathbf{b} \beta C T F$ in $\mathrm{H} 4$ cells, as detected by ELISA following incubation with media, or siRNA targeting either total PICALM (sequence A), PICALM isoform 1, PICALM isoform 2 or GFP for $48 \mathrm{~h}$. Data are expressed as \% of media control and are mean \pm SEM, ${ }^{*} \mathrm{p}<0.01,{ }^{* * *} \mathrm{p}<0.001$ significantly different to GFP siRNA with a one-way analysis of variance and Dunnett's multiple comparison test, $n=5$ (a) and, $n=4-5(\mathbf{b})$

\section{Discussion}

We have demonstrated that reducing the expression of PICALM or clathrin inhibits CME to a similar extent and reduces $\beta$-secretase-mediated cleavage of APP but only PICALM siRNA affects the levels of APP. Thus PICALM can influence the processing of APP via more than one route possibly contributing to its role as a risk factor for AD.

The gene for PICALM gives rise to a number of isoforms [27, 33-35] of which 4 appear to be the most common [30]. In the H4 cells we consistently found isoforms 1 and 2 with apparent higher expression levels of isoform 2 but did not detect isoforms 3 or 4 . Therefore all further work concentrated on isoforms 1 and 2. A similar pattern has been described by other authors with isoforms 1 and 2 being the predominant forms [24, 34-37]. Our two different siRNA sequences (Seqs. A and B), directed against a region common to all four isoforms, consistently demonstrated a large reduction in the expression of PICALM with no significant toxic effects from either measure. Thus our data suggest that the reduction was specific to PICALM and that PICALM is not critical for cell survival.

Reducing PICALM expression by siRNA significantly inhibited the uptake of transferrin by functional CME in the $\mathrm{H} 4$ cells suggesting that, in these cells, PICALM is essential for normal levels of CME to occur, probably due to its involvement in the formation of clathrin-coated vesicles $[24,35]$. These data agree with other findings on functional CME where reducing $[24,38,39]$ or increasing $[35,38]$ the expression of PICALM resulted in changes in transferrin uptake. Other studies have described no effect of siRNA for PICALM on transferrin uptake [37, $40,41]$ but all these studies only measured endocytosis at short time intervals of 5-10 min so would not have seen effects occurring up to $30 \mathrm{~min}$. Furthermore, this study used a quantitative assay in living cells unlike some other papers. It is also, however, possible that these findings could be explained by certain cells being capable of overcoming PICALM depletion by increased reliance on its homologue, AP180 [24, 33].

The consequent decrease in functional endocytosis following PICALM depletion does not involve dynamin 
a

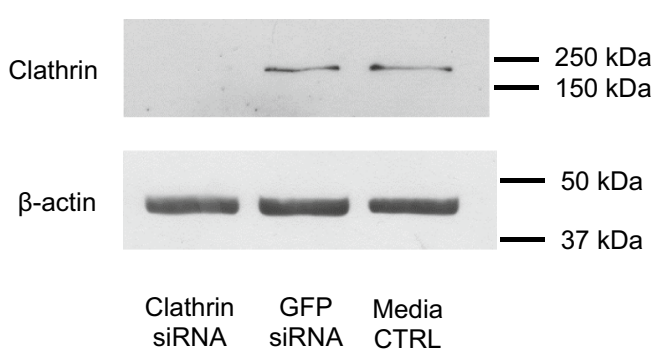

b

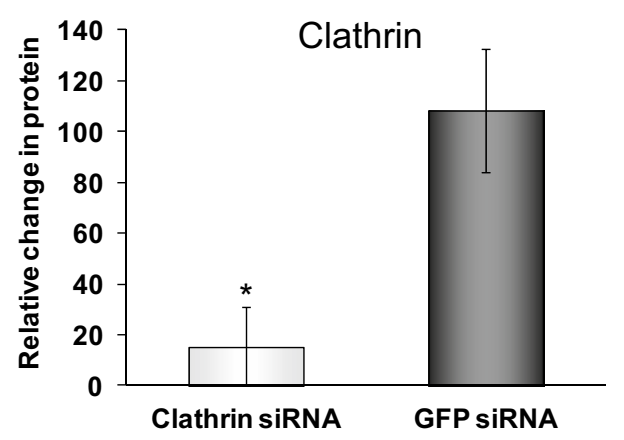

c

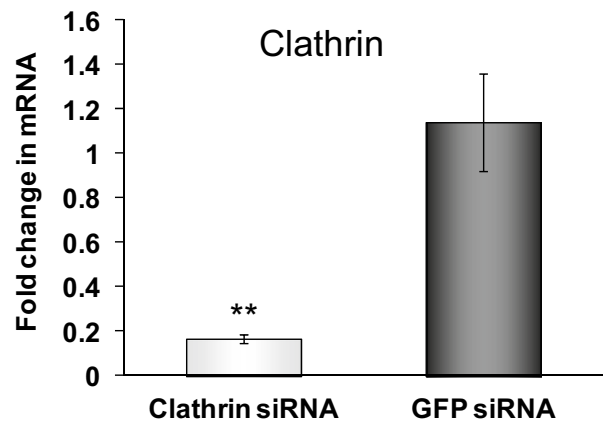

d

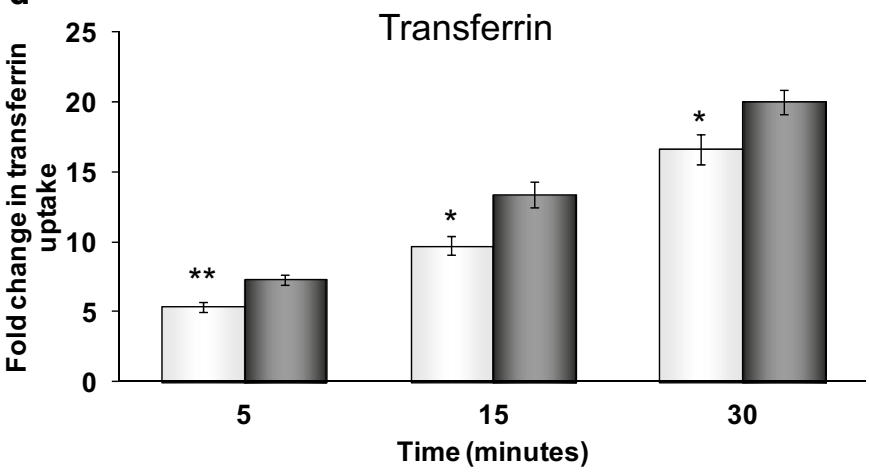

Time (minutes)

Clathrin

GFP

Fig. 8 Effects of clathrin siRNA on clathrin-mediated endocytosis. H4 cells were incubated with media, control siRNA (GFP siRNA) or siRNA targeting clathrin heavy chain (Clathrin siRNA) for $48 \mathrm{~h}$. a Representative immunoblot of clathrin expression and $\mathbf{b}$ following densitometric analysis. Data are presented as a percentage of the untreated media control after normalisation to house-keeping protein levels and are mean \pm SEM, $n=3$, ${ }^{*} p<0.05$ significantly different to GFP siRNA with an unpaired Student's $t$ test. c Clathrin mRNA expression levels using quantitative PCR, normalised to the housekeeping gene $18 \mathrm{~S}$ and relative to the untreated cells. Data are presented as mean $\pm S E M, n=6,{ }^{* *} p<0.01$ significantly different to GFP siRNA with Mann-Whitney-U.d H4 cells were incubated with $100 \mathrm{nM}$ Alexa488-Tf for 5, 15 or 30, minutes then trypsinised and analysed by flow cytometry. Mean fluorescent intensity (MFI) data are expressed as fold change over untreated control cells (0 min Alexa488-Tf) and are mean \pm SEM ${ }^{*} p<0.05,{ }^{* *} p<0.01$ significantly different to GFP siRNA with an unpaired Student's $t$ test, $n=4-5$

or a change in the levels of clathrin since neither mRNA nor protein levels for $\mathrm{CHC}$ were altered by knockdown of PICALM. However, the localisation of clathrin in the transgolgi network was reduced by PICALM depletion possibly due to redistribution in the cell since overall protein expression was unaltered. A reduction in clathrin expression in the transgolgi network has been described previously for both decreasing [24] and increasing [35] the expression of PICALM, suggesting that PICALM is important for the correct localisation of clathrin in the cell. PICALM itself was not present in the perinuclear region, confirming previous findings $[24,35]$, so it is most likely to have an indirect effect on the targeting of clathrin to different subcellular areas. The control of trafficking 
a

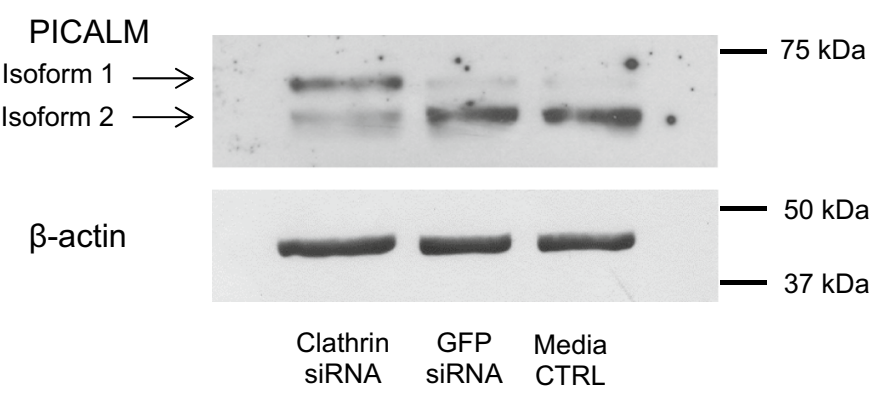

b
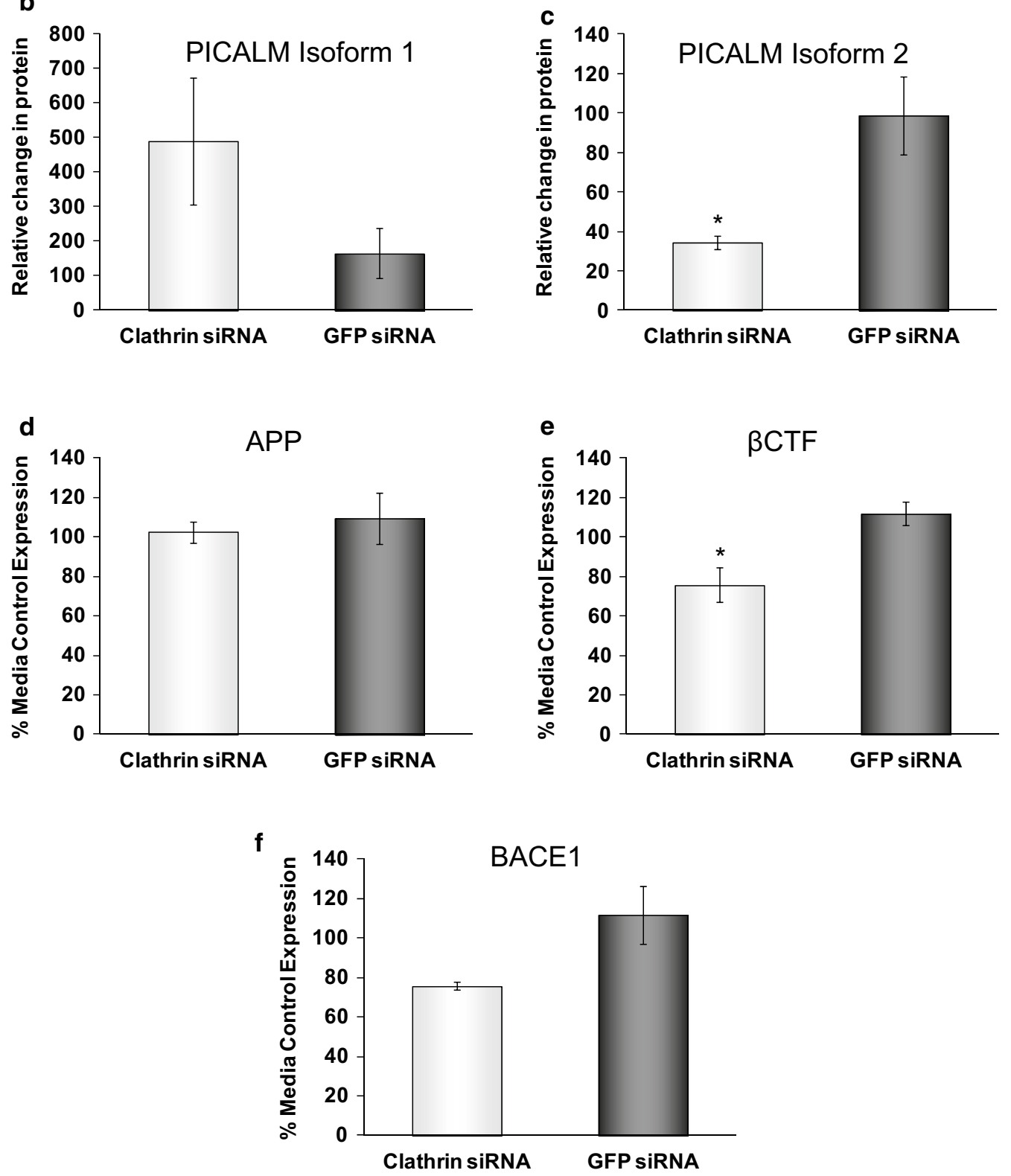

Fig. 9 Differential effects of clathrin siRNA on isoforms 1 and 2 of PICALM and APP processing. H4 cells were incubated with media, control siRNA (GFP siRNA) or siRNA targeting clathrin heavy chain (Clathrin siRNA) for $48 \mathrm{~h}$. a Representative immunoblot of isoforms 1 and 2 of PICALM and $\mathbf{b}$ following densitometric analysis of isoform 1 and $\mathbf{c}$ isoform 2. Data are presented as a percentage of the untreated media control after normalisation to house-keeping protein levels and are mean \pm SEM. Levels of $\mathbf{d}$ APP, e $\beta C T F$ and $\mathbf{f}$ BACE1 as detected by ELISA. Data are expressed as \% of media control and are mean \pm SEM. $N=3$ for all, ${ }^{*} \mathrm{p}<0.05$ significantly different to GFP siRNA with an unpaired Student's $t$ test 
between the early endosome and the transgolgi network involves many proteins so depletion of PICALM could affect multiple targets [42]. PICALM is very important for controlling the endocytosis of R-SNAREs (Soluble NSF Attachment Protein Receptors) such as VAMP2, 3 and 8 which are necessary for the fusion of endocytic vesicles containing various cargoes with endosomes or the plasma membrane for recycling [43]. VAMP3 is also involved with the tethering of endosomes to the transgolgi network [42] so affecting VAMP3 function by depleting PICALM could reduce the amount of clathrin in the transGolgi network. Depleting cells of clathrin using siRNA to clathrin heavy chain significantly reduced transferrin uptake as expected [44]. Interestingly, we saw a different time course for depletion of clathrin or PICALM to affect significantly the uptake of transferrin. Al Soraj and co-workers [44] found the largest effect of clathrin depletion was at early time points and suggested that, at later time points, the effect of reduced recycling of transferrin from endosomes became more important. Thus the effects of PICALM depletion may be affected less by recycling from endosomes.

Consistent with previous findings showing that APP is internalised by endocytosis [45] and that PICALM is involved in this process [41], we saw a decrease in the expression of intracellular APP after depletion of PICALM. The specificity of this effect on APP to PICALM was confirmed using a second total PICALM siRNA sequence. Xiao et al. [41] did not see an effect on full-length APP after depletion of PICALM possibly due to their use of cells overexpressing APP where normal physiological mechanisms might be affected. However, the consequence of depleting PICALM on APP levels is additional to an effect on the formation of clathrincoated vesicles as reducing clathrin did not affect APP levels. PICALM can affect transcription [46], but the levels of APP mRNA were not altered by depleting PICALM so the change in APP is very unlikely to be due to reduced protein synthesis. It was also not due to a change in the subcellular location of APP in our cells. It is therefore more likely that this reduction in APP is due to the disruption of R-SNARE proteins by PICALM depletion. Changes in VAMP3 and VAMP 8 have been postulated to explain the increased levels of total cellular cholesterol seen after PICALM knockdown [47]. It is possible that the alterations in APP we see after PICALM siRNA could also be partly due to changes in cellular cholesterol homeostasis.

Depleting PICALM expression decreased $\beta$-secretase cleavage of APP as the levels of $\beta C$ TF were reduced and a decrease in the sAPP $\beta /$ sAPP $\alpha$ ratio was seen. $\alpha$-secretase activity was unaffected by depletion of PICALM. A role for PICALM in targeting CTF fragments of APP for degradation by autophagy has been suggested [48]. Thus an increase in $\beta$-CTF levels would be expected if PICALM levels are reduced but we saw the reverse. Therefore the decrease in $\beta$-CTF levels must occur upstream of autophagic processes, most likely via an effect on $\beta$-secretase. Although $\beta$-secretase cleavage was affected by knockdown of PICALM, the levels of A $\beta 40$ were unaffected agreeing with other studies [39, 41, 49, $50]$. $\beta$ CTF is very likely to be involved in the development of the enlarged endosomes seen in both $\mathrm{AD}$ and Down Syndrome $[51,52]$. $\beta C T F$ is thought to activate rab5 via APPL1 (adaptor protein containing pleckstrin homology domain, phosphotyrosine binding domain and leucine zipper motif) [52] leading eventually to endosomal enlargement $[52,53]$. $\beta$ CTF may thus have an important role in the pathogenesis of $\mathrm{AD}[52,53]$ and therefore decreasing PICALM expression would be protective by lowering $\beta C T F$ production. The decrease in $\beta C T F$ we see is likely to be due in part to the reduction in endocytosis produced by PICALM depletion decreasing the entry of APP into the cells as it was also seen after knock down of clathrin. However, the effect of PICALM depletion on $\beta C T F$ was greater than that produced by clathrin, providing further support for an effect of PICALM on APP independent of CME.

Previous work has shown that PICALM affects the endocytosis of $\gamma$-secretase and this was proposed to explain the effects of depletion of PICALM on A $\beta$ generation [49]. However, we have clearly demonstrated here an effect on the cleavage of APP by $\beta$-secretase after depletion of PICALM probably due to less APP being endocytosed into early endosomes to encounter $\beta$-secretase. There was no apparent effect on the distribution of BACE1 in PICALM-depleted cells compared to control cells. Both PICALM and clathrin depletion reduced the levels of BACE mRNA by about $20 \%$ and PICALM depletion reduced protein levels by $44.45 \%$ with a trend for a decrease of $39.5 \%$ seen with CHC siRNA, suggesting an effect on BACE synthesis. The reduction in BACE1 levels is unlikely to be due to an effect on endocytosis as it was seen at the mRNA level and clathrin siRNA, which reduced functional endocytosis, did not affect BACE1 protein expression. However, this reduction in BACE1 levels is unlikely to explain the 35-60 \% decrease in $\beta$ CTF production obtained with PICALM and CHC depletion as a $50 \%$ decrease in BACE1 levels in transgenic BACE1 \pm mice resulted in reductions in $A \beta$ of no more than $12-40 \%[54,55]$. Therefore it appears unlikely that a change in the levels of $\beta$-secretase itself is responsible for the effects of PICALM and clathrin depletion on $\beta C$ TF levels.

Having examined the effect of depletion of total PICALM on APP metabolism and, given that the 
expression of isoform 1 was lower than isoform 2 in $\mathrm{H} 4$ cells, we investigated whether the isoforms had differential effects on APP endocytosis and processing. We depleted isoform 1 and 2 individually using specific siRNAs which did not significantly affect the other isoform thus confirming that the two bands we saw in the $\mathrm{H} 4$ cells were indeed isoform 1 and 2. Interestingly, depletion of either isoform alone had no significant effect on the levels of APP or $\beta$ CTF so both PICALM isoforms must be involved in functional endocytosis in the H4 cells. However, the differential effect of clathrin depletion on the expression of the isoforms at both the mRNA and protein level does suggest that they may have different roles in CME. Clathrin depletion increased both the protein and mRNA for isoform 1 but decreased isoform 2 protein without altering the mRNA. The discrepancy for isoform 2 may be due to differences in mRNA stability between the two isoforms. The increase in one PICALM isoform and the decrease in the other may explain why clathrin depletion had no effect on APP levels. The intracellular localisation of total PICALM was altered by clathrin depletion which could reflect differential changes in the expression of isoforms 1 and 2. We could not investigate this finding further to understand the mechanism involved as there are no commercial antibodies available which can distinguish between isoforms 1 and 2. Our findings from the eQTL data sets, showing an association between a decrease in isoform 2 mRNA expression but no effects on isoform $1 \mathrm{mRNA}$ for the Harold and coworkers [2] and IGAP [4] SNPs, are interesting given that we and others find that control cells generally have higher levels of isoform 2 than isoform 1 . These data suggest that the ratio of the two isoforms may be important physiologically. However, given that we found that both isoforms needed to be knocked down to decrease APP and $\beta C T F$ expression, it is currently unclear how the differential association of the GWAS PICALM SNPs with isoform expression are related to the processing of APP. Our data suggest that the relationship between PICALM and APP processing is likely to be highly complex and requires further investigation. There are very few published studies examining the biological effects of manipulating the isoforms of PICALM. Kanatsu and colleagues [39] looked at the effects of overexpressing isoforms 1 and 2 on $A \beta$ secretion but did not see any differences. Other workers have shown reversal of the protective effect of depletion of PICALM yeast homologue isoforms 1 and 2 by mammalian isoform 2 (mammalian isoform 1 expression was toxic in yeast) [26]. Parikh et al. [27] examined the association of mRNAs for various splice variants of PICALM with a SNP encoding a polymorphism in the gene associated with $\mathrm{AD}$ and found increased total PICALM
Table 1 siRNA sequences used to knock down protein expression

\begin{tabular}{lll}
\hline siRNA target & Sequence & References \\
\hline Total PICALM 'A' & GCAUACAAUGAAGGAAUUAdTdT & Custom-designed \\
Total PICALM 'B'a & AAGCCAAGAAUUGCUAUGAdTdT & Custom-designed \\
PICALM isoform 1 & GCAAGUACAUGGGGAGAUCdTdT & Custom-designed \\
PICALM isoform 2 & GUACAUGGGGAGGAUUCACdTdT & Custom-designed \\
CHC & UAAUCCAAUUCGAAGACC & {$[43]$} \\
& AAUdTdT & \\
GFP & GGCUACGUCCAGGAGCGCA & {$[43]$} \\
& CCDTdT & \\
\hline
\end{tabular}

a The siRNA sequences for total PICALM were directed against regions of the mRNA common to isoforms 1-4

expression correlated with the protective allele but there was no significant correlation with the splice variants.

\section{Conclusions}

In conclusion, we have demonstrated that the depletion of PICALM in H4 cells has significant effects on the processing of APP, probably by reducing cleavage by $\beta$-secretase. The reduction in $\beta$ CTF production is particularly interesting as this is now increasingly thought to have toxic effects on cells independent of $A \beta$. These effects are likely to be mediated by at least two processes, a reduction in CME and an alteration in the endocytosis of endocytic vesicles. Based on our data and on evidence from the literature, we hypothesise that polymorphisms of PICALM could alter the expression of the protein over the lifetime of an individual which would be associated with either an increased risk of developing AD or a protective effect. Further studies are required to elucidate the relative importance of these different roles of PICALM and the relevance of the isoforms to APP processing.

\section{Methods}

\section{Materials}

All chemicals and reagents were purchased from SigmaAldrich, Poole, UK, Life Technologies (Invitrogen), Paisley, UK or Fisher Scientific, Leicester, UK and all reactions were performed at room temperature unless otherwise specified. All siRNA (sequences of 21-23 residues) were purchased from Eurofins Genomics, Ebersberg, Germany.

Antibodies were purchased as follows: Anti-APP (clone 22C11, MAB348, Millipore, Watford, UK), anti$\beta$-actin directly conjugated to horseradish peroxidase (HRP, clone AC-15, A3854) or GAPDH (clone GAPDH71.1, G9295, Sigma-Aldrich), anti-dynamin II (clone 27/ Dynamin II, 610263, BD Biosciences, Oxford, UK), anticlathrin heavy chain (clone 23/Clathrin Heavy Chain, 
Table 2 TaqMan probes used for real-time quantification of genes following siRNA

\begin{tabular}{ll}
\hline Gene & Gene expression assay \\
\hline Total PICALM & Hs00200318_m1 \\
PICALM isoform 1 & Hs00999727_m1 \\
PICALM isoform 2 & Hs01003584_m1 \\
PICALM isoform 3 & Hs01008128_m1 \\
CHC & Hs00964504_m1 \\
APP & Hs00169098_m1 \\
BACE1 (ß-secretase) & Hs01121195_m1 \\
POLR2A & Hs00172187_m1 \\
18S & Hs03928980_g1 \\
\hline
\end{tabular}

All Taqman probes were purchased from Applied Biosystems

610499, BD Biosciences), anti-PICALM (NBP1-86658, Novus Biologicals, Cambridge, UK), anti-BACE1 (clone M-83, sc-10748,Santa Cruz Biotechnology, Insight Biotechnology, Wembley UK) and anti-rabbit (PI-1000) and anti-mouse (PI-2000) antibodies conjugated to HRP (Vector Laboratories, Peterborough, UK).

\section{Cell culture}

Neuroglioma H4 cells (ECACC, Porton Down, UK) were cultured in Opti-MEM media containing Glutamax (Invitrogen) supplemented with $4 \%$ foetal bovine serum (FBS, Perbio Science UK Ltd, Cramlington, UK).

\section{Transfection of cells with siRNAs}

The expression of PICALM and clathrin heavy chain (CHC) was depleted using siRNA as previously described [43]. Briefly, H4 cells were seeded in a 6 well plate at a density of 150,000 cells per well $24 \mathrm{~h}$ prior to treatment. All procedures were performed in Opti-MEM in the absence of serum. Complexes were pre-formed between the oligonucleotides and oligofectamine (Invitrogen) using $50 \mathrm{pmol}$ oligonucleotide per $4 \mu$ l oligofectamine in a total volume of $200 \mu \mathrm{l}$ Opti-MEM. The complex was subsequently added to cells to give a final oligonucleotide concentration of $50 \mathrm{nM}$ in a total of $1 \mathrm{ml}$ OptiMEM. Cells were incubated with media, siRNA for green fluorescent protein (GFP) to control for off-target effects of oligofectamine and oligonucleotide, or the siRNA sequences in Table 1 for 4 h. $500 \mu$ l of Opti-MEM supplemented with $12 \%(\mathrm{v} / \mathrm{v})$ FBS was then added directly to the transfection mixture and cells were then incubated for $48 \mathrm{~h}$ and processed as required.

\section{Analysis of gene expression using quantitative PCR}

After siRNA treatment cells were lysed in Trizol ${ }^{\mathrm{TM}}$ reagent (Invitrogen) then total RNA was extracted and purified using RQ1 RNase-Free DNase (Promega, Southampton,
UK) followed by Qiagen RNeasy ${ }^{\mathrm{TM}}$ Mini kits (Qiagen, West Sussex, UK). cDNAs were synthesized from $800 \mathrm{ng}$ RNA with SuperScript ${ }^{\circledR}$ First-Strand Synthesis System (Invitrogen) using Oligo(dT) and Superscript ${ }^{\mathrm{TM}}$ II reverse transcriptase. Real-time PCR was carried out on the LightCycler ${ }^{\circledR} 2.0$ Real-Time PCR System (Roche Diagnostics $\mathrm{GmbH}$, Mannheim, Germany) using TaqMan gene expression assays (Table 2, Applied Biosystems, Paisley, UK) and LightCycler ${ }^{\circledR}$ TaqMan ${ }^{\circledR}$ Master hot start reaction mix (Roche). Reactions were carried out according to the manufacturer's protocols. Data were normalised either to polymerase (RNA) II (DNA directed) polypeptide A (POLR2A) or 18S RNA levels. Relative quantification was calculated using the $2^{-\Delta \Delta C t}$ method [56] using media controls as a reference group to quantify relative changes in target gene expression. Data are presented as fold change in expression normalised to the endogenous reference gene and relative to the untreated cDNA samples.

\section{Western blotting}

After siRNA treatment, cells were lysed as previously described [57] and total cell protein concentration was determined by bicinchoninic acid protein assay (Pierce, Rockford, IL, USA). Western Blotting was performed using standard methods. Briefly, samples were resolved on $10 \%$ polyacrylamide gels, transferred on to $0.45 \mu \mathrm{m}$ nitrocellulose membranes (Amersham Biosciences, Little Chalfont, UK), incubated with the relevant primary antibody and detected as previously described $[57,58]$.

\section{Internalisation of Alexa-488-labelled transferrin as a measure of CME}

This assay was performed according to Al-Soraj and coworkers [43] as described below. siRNA-transfected cells were washed twice with Opti-MEM at room temperature and incubated with Opti-MEM containing $0.2 \%(\mathrm{w} / \mathrm{v})$ BSA for $30 \mathrm{~min}$. Cells were then washed twice with OptiMEM at room temperature and incubated for 0-30 min with Opti-MEM containing 100 nM Alexa488-labelled transferrin (Alexa488-Tf; Life Technologies). Tissue culture plates were immediately placed on ice to inhibit further uptake and washed twice with ice-cold $0.1 \mathrm{M}$ phosphate-buffered saline (PBS) followed by a $1 \mathrm{~min}$ incubation in ice-cold acid wash $(0.2 \mathrm{M}$ acetic acid, $0.2 \mathrm{M}$ $\mathrm{NaCl}, \mathrm{pH} 2.0)$ to remove remaining surface label. Cells were then washed three times with PBS at room temperature and trypsinised. This reaction was inhibited with PBS supplemented with $1 \%(\mathrm{w} / \mathrm{v})$ BSA, trypsin inhibitor $(1 \mathrm{mg} / \mathrm{ml})$ and DNASE $(75 \mu \mathrm{g} / \mathrm{ml})$ before the cell suspension was washed with ice-cold PBS supplemented with $1 \%(\mathrm{w} / \mathrm{v})$ BSA and DNASE $(75 \mu \mathrm{g} / \mathrm{ml})$. Cell-associated fluorescence was detected by flow cytometry on a BD 
FACSCalibur $^{\mathrm{TM}}$, BD FACSCanto ${ }^{\mathrm{TM}}$ or BD FACSVerse ${ }^{\mathrm{TM}}$ analyser (BD Biosciences, Oxford, UK). Cell debris and aggregates were gated out and 10,000 events counted. Data are expressed as fold change over control cells and the mean fluorescent intensity (MFI) is the geometric mean. Data were analysed with Cyflogic 1.2.1 (Cyflo LTD, Turku, Finland) or BD FACSuite ${ }^{\mathrm{TM}}$ software.

\section{Quantification of APP}

APP in the lysed cells samples was quantified using the APP DuoSet (R\&D Systems, Abingdon, U.K.) following the manufacturer's guidelines $[57,58]$. Briefly, the capture antibody was used at $4 \mu \mathrm{g} / \mathrm{ml}$ in PBS overnight. Plates were blocked with $1 \%$ bovine serum albumin (BSA) and $5 \%$ sucrose in PBS and samples were quantified using a six point standard curve. The biotinylated detection antibody was used at $300 \mathrm{ng} / \mathrm{ml}$ and detected using streptavidin-HRP and o-phenylenediamine.

\section{Quantification of APP fragments: $A \beta 40$, sAPPa, sAPP $\beta$ and $\beta C T F$}

For analysis of $A \beta 40$, media was subjected to immunoprecipitation and ELISA as described previously $[57,58]$. Briefly, the ELISA employed the N-terminal A $\beta$ antibody $6 \mathrm{E} 10(5 \mathrm{mg} / \mathrm{ml}$, Cambridge Bioscience Ltd, Cambridge, UK), as the capture antibody and affinity-purified BAM401AP $(0.45 \mu \mathrm{g} / \mathrm{ml}$, Autogen Bioclear, Calne, UK), specific to the C-terminus of human $A \beta 40$, as the detection antibody. To determine the effect of siRNAs on sAPP $\alpha$ and sAPP $\beta$, media was tested in sandwich ELISAs (IBL, Hamburg, Germany) and intracellular $\beta C T F$ levels were detected by ELISA (IBL).

\section{Effect of siRNA to total PICALM on H4 cell viability}

Viability studies were performed after incubation with siRNA to total PICALM for 48 and $72 \mathrm{~h}$ using the CellTiter $96^{\circledR}$ MTS Aqueous One Solution Cell Proliferation Assay (Promega) following the manufacturer's guidelines. The total number of cells was also counted using a $\mathrm{Z}^{\mathrm{TM}}$ Series Coulter Counter (Beckman Coulter (UK) Ltd, High Wycombe, UK).

\section{Immunocytochemistry}

$\mathrm{H} 4$ cells were plated on collagen-coated coverslips as previously described [57] and treated with various siRNA as described above for $48 \mathrm{~h}$. H4 cells were then fixed and processed for immunocytochemistry as previously described $[57,59]$. Cells were incubated with primary antibodies in blocking solution (PBS, $3 \%$ serum from the species used to raise the secondary antibody, $1 \%$ bovine serum albumin) overnight at $4{ }^{\circ} \mathrm{C}$. Antibody labelling was detected using appropriate secondary antibodies conjugated to biotin (1:500, Vector Laboratories) followed by avidin-FITC (1:600, Vector Laboratories). Coverslips were mounted on to glass slides using VECTASHIELD ${ }^{\circledR}$ HardSet $^{\mathrm{TM}}$ Mounting Medium (Vector Laboratories) with DAPI and visualized using a Leica SP5 confocal laser scanning microscope. GFP siRNA did not affect the localisation or expression of any of the proteins examined compared to media controls so the GFP siRNA images are shown for comparison with those obtained following siRNA for PICALM or clathrin.

\section{Statistical analysis}

Western blots were quantified using Image J, analysed as detailed previously [19] and expressed as relative density to the house keeping protein. Data generated in ELISA assays were quantified by comparing data to standard curves included on each plate using using Graphpad Prism $^{\circledR}$ 5. Results were first normalised to total protein concentration, where relevant and expressed as \% of media control values. Both SAPP $\beta$ and sAPP $\alpha$ were quantified in $\mathrm{ng} / \mathrm{ml}$ and then expressed as the ratio of sAPP $\beta$ to sAPP $\alpha$. Where there were only two factors, data were compared to GFP using unpaired Student's $t$ tests, at the two-tailed significance level. Elsewhere data were analysed with one-way ANOVA followed by the relevant post hoc test comparing all data to GFP.

Where necessary, data were transformed to fulfil the assumptions of normality and homoskedasticity and to therefore allow the use of parametric testing. If this proved impossible the equivalent non-parametric test was used.

All data used to produce Figs. 1, 3, 4, 5, 6, 7, 8 and 9 are shown in the Additional file 1.

\section{Additional file}

Additional file 1. These data were used to produce the graphs shown in Figures $1,3,4,5,6,7,8$ and 9 .

\section{Abbreviations}

A $\beta$ : $\beta$-amyloid; AD: Alzheimer's disease; Alexa488-Tf: Alexa488-labelled transferrin; APP: amyloid precursor protein; BACE1: $\beta$-site APP cleaving enzyme;

$\beta$-CTF: $\beta$-C-terminal fragment; BIN1: bridging integrator 1 ; $\mathrm{CHC}$ : clathrin heavy chain; CME: clathrin-mediated endocytosis; $\mathrm{eQTL}$ : expression quantitative trait loci; FBS: foetal bovine serum; GFP: green fluorescent protein; GWAS: Genome Wide Association Study; HRP: horseradish peroxidase; IGAP: International Genomics of Alzheimer's disease Project; MFI: mean fluorescent intensity; PBS: phosphate-buffered saline; PICALM: phosphatidylinositol binding clathrin assembly protein; Pol II: RNA polymerase II; R-SNAREs: soluble NSF attachment protein receptors; SORL1: sortilin-related receptor.

\section{Authors' contributions}

RST, EJK, LJ and JW conceived the study and designed the experiments. RST and $\mathrm{AH}$ performed the siRNA, Western blotting and ELISAs. RST performed the RT-qPCR and the transferrin assays. EJK carried out the confocal microscopy. AG investigated the association of GWAS SNPs with isoform expression. RST analyzed the data and EJK assisted with data interpretation. EJK, RST and LJ wrote the manuscript. All authors read and approved the final version of the manuscript. 


\begin{abstract}
Author details
1 School of Pharmacy and Pharmaceutical Sciences, Cardiff University, Redwood Building, King Edward VII Avenue, Cardiff CF10 3NB, UK. ${ }^{2}$ MRC Centre for Neuropsychiatric Genetics and Genomics, School of Medicine, Cardiff University, Hadyn Ellis Building, Maindy Road, Cardiff CF24 4HQ, UK. ${ }^{3}$ Present Address: West Midlands Regional Genetics Laboratory, Birmingham Women's NHS Foundation Trust, Mindelsohn Way, Edgbaston, Birmingham B15 2TG, UK.
\end{abstract}

\section{Acknowledgements}

We would like to thank the Allison family for their generous donation to this research. We would also like to thank Dr Richard Abraham, Julian Bade, Emily Kirkham, Rachel Raybould, Julia Schappinger and Siobhan Smith for their essential assistance with this work.

\section{Competing interests}

The authors declare that they have no competing interests.

\section{Availability of data and material}

The datasets supporting the conclusions of this article are included in a spreadsheet within Additional file 1 of the article where possible.

\section{Ethics approva}

This study used previously published data obtained from publicly available online repositories: Gibbs et al. eQTL dataset [31] (GEO Accession Number: GSE15745; dbGAP Study Accession: phs000249.v1.p1); UK Brain Expression Consortium eQTL dataset [32] (www.braineac.org). Therefore no ethical permission is required to use these data. All data are anonymised so it is not possible to trace the original brain donors.

\section{Funding}

Part of the data collection and analysis for this study was supported by the Medical Research Council (MRC UK, MR/L010305/1). No other funding was obtained for this study.

Received: 25 February 2016 Accepted: 11 July 2016 Published online: 18 July 2016

\section{References}

1. Lambert JC, Heath S, Even G, Campion D, Sleegers K, Hiltunen M, Combarros O, Zelenika D, Bullido MJ, Tavernier B, et al. Genome-wide association study identifies variants at CLU and CR1 associated with Alzheimer's disease. Nat Genet. 2009:41:1094-9.

2. Harold D, Abraham R, Hollingworth P, Sims R, Gerrish A, Hamshere ML, Pahwa JS, Moskvina V, Dowzell K, Williams A, et al. Genome-wide association study identifies variants at CLU and PICALM associated with Alzheimer's disease. Nat Genet. 2009:41:1088-93.

3. Jones L, Lambert JC, Wang L-S, Choi SH, Harold D, Vedernikov A, EscottPrice V. Convergent genetic and expression data implicate immunity in Alzheimer's disease. Alzheimer's Dement. 2015;11:658-71.

4. Lambert JC, Ibrahim-Verbaas CA, Harold D, Naj AC, Sims R, Bellenguez C, DeStafano AL, Bis JC, Beecham GW, Grenier-Boley B, et al. Meta-analysis of 74,046 individuals identifies 11 new susceptibility loci for Alzheimer's disease. Nat Genet. 2013;45:1452-8.

5. Seshadri S, Fitzpatrick AL, Ikram MA, DeStefano AL, Gudnason V, Boada M, Bis JC, Smith AV, Carassquillo MM, Lambert JC, et al. Genome-wide analysis of genetic loci associated with Alzheimer disease. JAMA J Am Med Assoc. 2010:303:1832-40

6. Hardy J, Allsop D. Amyloid deposition as the central event in the aetiology of Alzheimer's disease. Trends Pharmacol Sci. 1991;12:383-8.

7. Koo EH, Squazzo SL, Selkoe DJ, Koo CH. Trafficking of cell-surface amyloid beta-protein precursor. I. Secretion, endocytosis and recycling as detected by labeled monoclonal antibody. J Cell Sci. 1996;109:991-8.

8. Yamazaki T, Koo EH, Selkoe DJ. Trafficking of cell-surface amyloid betaprotein precursor. II. Endocytosis, recycling and lysosomal targeting detected by immunolocalization. J Cell Sci. 1996;109:999-1008.

9. Sinha S, Anderson JP, Barbour R, Basi GS, Caccavello R, Davis D, Doan M, Dovey HF, Frigon N, Hong J, et al. Purification and cloning of amyloid precursor protein beta-secretase from human brain. Nature. 1999:402:537-40.

10. Vassar R, Bennett BD, Babu-Khan S, Kahn S, Mendiaz EA, Denis P, Teplow $D B$, Ross S, Amarante P, Loeloff R, et al. Beta-secretase cleavage of Alzheimer's amyloid precursor protein by the transmembrane aspartic protease BACE. Science. 1999;286:735-41.

11. Yan R, Bienkowski MJ, Shuck ME, Miao H, Tory MC, Pauley AM, Brashier JR, Stratman NC, Mathews WR, Buhl AE, et al. Membrane-anchored aspartyl protease with Alzheimer's disease beta-secretase activity. Nature. 1999;402:533-7.

12. Citron M. Strategies for disease modification in Alzheimer's disease. Nat Rev Neurosci. 2004;5:677-85.

13. Edbauer D, Winkler E, Regula JT, Pesold B, Steiner H, Haass C. Reconstitution of gamma-secretase activity. Nat Cell Biol. 2003;5:486-8.

14. Kimberly WT, LaVoie MJ, Ostaszewski BL, Ye W, Wolfe MS, Selkoe DJ. Gamma-secretase is a membrane protein complex comprised of presenilin, nicastrin, Aph-1, and Pen-2. Proc Natl Acad Sci USA. 2003;100:6382-7.

15. Takasugi N, Tomita T, Hayashi I, Tsuruoka M, Niimura M, Takahashi Y, Thinakaran G, Iwatsubo T. The role of presenilin cofactors in the gammasecretase complex. Nature. 2003:422:438-41.

16. Allinson TM, Parkin ET, Turner AJ, Hooper NM. ADAMs family members as amyloid precursor protein alpha-secretases. J Neurosci Res. 2003;74:342-52.

17. Asai M, Hattori C, Szabo B, Sasagawa N, Maruyama K, Tanuma S, Ishiura S. Putative function of ADAM9, ADAM10, and ADAM17 as APP alphasecretase. Biochem Biophys Res Commun. 2003;301:231-5.

18. Grbovic OM, Mathews PM, Jiang Y, Schmidt SD, Dinakar R, Summers-Terio NB, Ceresa BP, Nixon RA, Cataldo AM. Rab5-stimulated up-regulation of the endocytic pathway increases intracellular beta-cleaved amyloid precursor protein carboxyl-terminal fragment levels and Abeta production. J Biol Chem. 2003;278:31261-8.

19. Thomas RS, Lelos MJ, Good MA, Kidd EJ. Clathrin-mediated endocytic proteins are upregulated in the cortex of the Tg2576 mouse model of Alzheimer's disease-like amyloid pathology. Biochem Biophys Res Commun. 2011;415:656-61.

20. Cataldo AM, Barnett JL, Pieroni C, Nixon RA. Increased neuronal endocytosis and protease delivery to early endosomes in sporadic Alzheimer's disease: neuropathologic evidence for a mechanism of increased betaamyloidogenesis. J Neurosci. 1997;17:6142-51.

21. Cataldo AM, Peterhoff CM, Troncoso JC, Gomez-Isla T, Hyman BT, Nixon RA. Endocytic pathway abnormalities precede amyloid beta deposition in sporadic Alzheimer's disease and Down syndrome: differential effects of APOE genotype and presenilin mutations. Am J Pathol. 2000;157:277-86.

22. Carey RM, Balcz BA, Lopez-Coviella I, Slack BE. Inhibition of dynamindependent endocytosis increases shedding of the amyloid precursor protein ectodomain and reduces generation of amyloid beta protein. BMC Cell Biol. 2005;6:30.

23. Cirrito JR, Kang JE, Lee J, Stewart FR, Verges DK, Silverio LM, Bu G, Mennerick S, Holtzman DM. Endocytosis is required for synaptic activitydependent release of amyloid-beta in vivo. Neuron. 2008;58:42-51.

24. Meyerholz A, Hinrichsen L, Groos S, Esk PC, Brandes G, Ungewickell EJ. Effect of clathrin assembly lymphoid myeloid leukemia protein depletion on clathrin coat formation. Traffic. 2005;6:1225-34.

25. Barral S, Bird T, Goate A, Farlow MR, Diaz-Arrastia R, Bennett DA, Graff-Radford N, Boeve BF, Sweet RA, Stern Y, et al. Genotype patterns at PICALM, CR1, BIN1, CLU, and APOE genes are associated with episodic memory. Neurology. 2012;78:1464-71.

26. D'Angelo F, Vignaud H, Di Martino J, Salin B, Devin A, Cullin C, Marchal $C$. A yeast model for amyloid-beta aggregation exemplifies the role of membrane trafficking and PICALM in cytotoxicity. Dis Models Mech. 2013;6:206-16.

27. Parikh I, Fardo DW, Estus S. Genetics of PICALM expression and Alzheimer's disease. PLoS One. 2014;9:e91242.

28. Kok EH, Luoto T, Haikonen S, Goebeler S, Haapasalo H, Karhunen PJ. CLU, CR1 and PICALM genes associate with Alzheimer's-related senile plaques. Alzheimers Res Ther. 2011;3:12.

29. Ando K, Brion JP, Stygelbout V, Suain V, Authelet M, Dedecker R, Chanut A, Lacor P, Lavaur J, Sazdovitch V, et al. Clathrin adaptor CALM/PICALM is associated with neurofibrillary tangles and is cleaved in Alzheimer's brains. Acta Neuropathol. 2013:125:861-78. 
30. NCBI reference sequence database. http://www.ncbi.nlm.nih.gov/refseq/. Accessed 5 Oct 15.

31. Gibbs JR, van der Brug MP, Hernandez DG, Traynor BJ, Nalls MA, Lai SL, Arepalli S, Dillman A, Rafferty IP, Troncoso J, et al. Abundant quantitative trait loci exist for DNA methylation and gene expression in human brain. PLoS Genet. 2010;6:e1000952.

32. Trabzuni D, Ryten M, Walker R, Smith C, Imran S, Ramasamy A, Weale $M E$, Hardy J. Quality control parameters on a large dataset of regionally dissected human control brains for whole genome expression studies. $J$ Neurochem. 2011;119:275-82.

33. Dreyling MH, Martinez-Climent JA, Zheng M, Mao J, Rowley JD, Bohlander SK. The $t(10 ; 11)(p 13 ; q 14)$ in the U937 cell line results in the fusion of the AF10 gene and CALM, encoding a new member of the AP-3 clathrin assembly protein family. Proc Natl Acad Sci USA. 1996;93:4804-9.

34. Jones L, Harold D, Williams J. Genetic evidence for the involvement of lipid metabolism in Alzheimer's disease. Biochim Biophys Acta. 2010;1801:754-61.

35. Tebar F, Bohlander SK, Sorkin A. Clathrin assembly lymphoid myeloid leukemia (CALM) protein: localization in endocytic-coated pits, interactions with clathrin, and the impact of overexpression on clathrin-mediated traffic. Mol Biol Cell. 1999;10:2687-702.

36. Baig S, Joseph SA, Tayler H, Abraham R, Owen MJ, Williams J, Kehoe PG, Love S. Distribution and expression of picalm in Alzheimer disease. $J$ Neuropathol Exp Neurol. 2010;69:1071-7.

37. Huang F, Khvorova A, Marshall W, Sorkin A. Analysis of clathrin-mediated endocytosis of epidermal growth factor receptor by RNA interference. J Biol Chem. 2004;279:16657-61.

38. Scotland PB, Heath $J \mathrm{~L}$, Conway AE, Porter NB, Armstrong MB, Walker JA, Klebig ML, Lavau CP, Wechsler DS. The PICALM protein plays a key role in iron homeostasis and cell proliferation. PLoS One. 2012;7:e44252.

39. Kanatsu K, Morohashi Y, Suzuki M, Kuroda H, Watanabe T, Tomita T, Iwatsubo T. Decreased CALM expression reduces Abeta42 to total Abeta ratio through clathrin-mediated endocytosis of gamma-secretase. Nat Commun. 2014;5:3386.

40. Harel A, Wu F, Mattson MP, Morris CM, Yao PJ. Evidence for CALM in directing VAMP2 trafficking. Traffic. 2008;9:417-29.

41. Xiao Q, Gil SC, Yan P, Wang Y, Han S, Gonzales E, Perez R, Cirrito JR, Lee JM. Role of phosphatidylinositol clathrin assembly lymphoid-myeloid leukemia (PICALM) in intracellular amyloid precursor protein (APP) processing and amyloid plaque pathogenesis. J Biol Chem. 2012;287:21279-89.

42. Lu L, Hong WJ. From endosomes to the trans-Golgi network. Semin Cell Dev Biol. 2014:31:30-9.

43. Miller SE, Sahlender DA, Graham SC, Honing S, Robinson MS, Peden AA, Owen DJ. The molecular basis for the endocytosis of small R-SNAREs by the clathrin adaptor CALM. Cell. 2011;147:1118-31.

44. Al Soraj M, He L, Peynshaert K, Cousaert J, Vercauteren D, Braeckmans K, De Smedt SC, Jones AT. siRNA and pharmacological inhibition of endocytic pathways to characterize the differential role of macropinocytosis and the actin cytoskeleton on cellular uptake of dextran and cationic cell penetrating peptides octaarginine (R8) and HIV-Tat. J Controll Release. 2012:161:132-41.

45. Koo EH, Squazzo SL. Evidence that production and release of amyloid beta-protein involves the endocytic pathway. J Biol Chem. 1994;269:17386-9.
46. Vecchi M, Polo S, Poupon V, van de Loo JW, Benmerah A, Di Fiore PP. Nucleocytoplasmic shuttling of endocytic proteins. J Cell Biol. 2001;153:1511-7.

47. Mercer JL, Argus JP, Crabtree DM, Keenan MM, Wilks MQ, Chi J-TA, Bensinger SJ, Lavau CP, Wechsler DS. Modulation of PICALM levels perturbs cellular cholesterol homeostasis. PLoS One. 2015;10:e0129776.

48. Tian Y, Chang JC, Fan EY, Flajolet M, Greengard P. Adaptor complex AP2/PICALM, through interaction with LC3, targets Alzheimer's APPCTF for terminal degradation via autophagy. Proc Natl Acad Sci USA. 2013;110:17071-6.

49. Bali J, Gheinani AH, Zurbriggen S, Rajendran L. Role of genes linked to sporadic Alzheimer's disease risk in the production of beta-amyloid peptides. Proc Natl Acad Sci USA. 2012;109:15307-11.

50. Wu F, Matsuoka Y, Mattson MP, Yao PJ. The clathrin assembly protein AP180 regulates the generation of amyloid-beta peptide. Biochem Biophys Res Commun. 2009;385:247-50.

51. Jiang Y, Mullaney KA, Peterhoff CM, Che S, Schmidt SD, Boyer-Boiteau A, Ginsberg SD, Cataldo AM, Mathews PM, Nixon RA. Alzheimer's-related endosome dysfunction in Down syndrome is Abeta-independent but requires APP and is reversed by BACE-1 inhibition. Proc Natl Acad Sci USA. 2010;107:1630-5

52. Kim S, Sato Y, Mohan PS, Peterhoff C, Pensalfini A, Rigoglioso A, Jiang $Y$, Nixon RA. Evidence that the rab5 effector APPL1 mediates APP-betaCTFinduced dysfunction of endosomes in Down syndrome and Alzheimer's disease. Mol Psychiatry. 2015;. doi:10.1038/mp.2015.97.

53. Ihara Y, Morishima-Kawashima M, Nixon R. The ubiquitin-proteasome system and the autophagic-lysosomal system in Alzheimer disease. Cold Spring Harbour Perspect Med. 2012;2:a006361.

54. Laird FM, Cai HB, Savonenko AV, Farah MH, He KW, Melnikova T, Wen HJ, Chiang HC, Xu GL, Koliatsos VE, et al. BACE1, a major determinant of selective vulnerability of the brain to amyloid-beta amyloidogenesis, is essential for cognitive, emotional, and synaptic functions. J Neurosci. 2005:25:11693-709.

55. McConlogue L, Buttini M, Anderson JP, Brigham EF, Chen KS, Freedman SB, Games D, Johnson-Wood K, Lee M, Zeller M, et al. Partial reduction of BACE1 has dramatic effects on Alzheimer plaque and synaptic pathology in APP transgenic mice. J Biol Chem. 2007;282:26326-34.

56. Livak KJ, Schmittgen TD. Analysis of relative gene expression data using real-time quantitative PCR and the 2(-Delta Delta C(T)) Method. Methods. 2001;25:402-8.

57. Thomas RS, Liddell JE, Murphy LS, Pache DM, Kidd EJ. An antibody to the beta-secretase cleavage site on amyloid-beta-protein precursor inhibits amyloid-beta production. J Alzheimers Dis. 2006;10:379-90.

58. Thomas RS, Liddell JE, Kidd EJ. Anti-amyloid precursor protein immunoglobulins inhibit amyloid-beta production by steric hindrance. FEBS $\mathrm{J}$. 2011;278:167-78.

59. Thomas RS, Hvoslef-Eide M, Good MA, Kidd EJ. Inhibition of amyloid-beta production by anti-amyloid precursor protein antibodies in primary mouse cortical neurones. NeuroReport. 2013;24:1058-61.

\section{Submit your next manuscript to BioMed Central and we will help you at every step:}

- We accept pre-submission inquiries

- Our selector tool helps you to find the most relevant journal

- We provide round the clock customer support

- Convenient online submission

- Thorough peer review

- Inclusion in PubMed and all major indexing services

- Maximum visibility for your research

Submit your manuscript at www.biomedcentral.com/submit
() BioMed Central 